\title{
RESENHA
}

\section{Aprender Sempre Mais e Mais É Possível!}

\author{
Jorgiana Baú \\ Universidade do Oeste de Santa Catarina - Campus Joaçaba \\ Olga Mitsue Kubo \\ Universidade Federal de Santa Catarina
}

DA ROS, Silvia Zanatta. (2002). Pedagogia e Mediação em Reuven Feuerstein: O processo de mudança em adultos com história de deficiência. São Paulo: Editora Plexus. 130 p.

"Mediar uma atitude otimista em relação à vida e em relação ao sujeito mesmo não é somente fazê-lo sonhar, mas é the dar os meios de materializar seu otimismo" (Reuven Feuerstein)

Você já ouviu falar em modificabilidade cognitiva? Que relação existe entre esse conceito e pessoas com história de deficiência? Será que pessoas com história de deficiência aprendem? Todas essas dúvidas podem ser elucidadas no livro "Pedagogia e Mediação em Reuven Feuerstein: O processo de mudança em adultos com história de deficiência", em que sua autora Silvia Zanatta Da Ros demonstra claramente os "processos de mudança" promovidos por mediação conforme a teoria feuersteniana e provê análises e informações que possibilitam construir e identificar respostas satisfatórias à pelo menos essas questões. $\mathrm{O}$ livro é resultado de seu trabalho para a defesa do título de doutora, em que a vivência segundo a perspectiva feuersteniana foi desenvolvida num grupo de seis adultos com história de deficiência, com idades entre 20 e 31 anos. Nessa experiência buscou-se romper a violência simbólica das palavras excepcionalidade e deficiência, direcionando a perspectiva do trabalho no sujeito que se modifica pela modificação do contexto cultural no qual é inserido. Vale a pena ler a obra sob a perspectiva de que quando o processo de aprendizagem é apropriadamente mediado, aprender sempre mais e mais é possível.

Feuerstein acredita na "exposição direta aos estímulos", sendo que, o processo de desenvolvimento e aprendizagem compreende a presença do outro ${ }^{1}$ nas representações culturais. O mediador conforme a perspectiva feuersteniana utiliza instrumentos afetivos e cognitivos para que os sujeitos com história de deficiência desenvolvam-se numa relação dinâmica: homem, cultura e seu movimento. Uma das decorrências de uma relação dessa natureza é a possibilidade de reorganização e ressignificação dessa relação, cujo produto é o reequacionamento do viver, sentir, pensar e significar.

Silvia demonstra claramente em seu livro todos os passos realizados durante sua pesquisa, assim como enfatiza e esclarece o papel dos mediadores (no caso, ela própria, e mais outra colega pedagoga), no exaustivo, porém, compensatório, programa aplicado durante seu doutorado, em que o processo de mediação fez com que cada estímulo oferecido aos sujeitos participantes sofresse transformação começando pelo ordenamento e pelo seqüenciamento de informações recebidas. Esse processo possibilita dar significado a essas informações, abstrair conceitos, ocorrendo, dessa forma, a modificabilidade cognitiva estrutural das pessoas com história de deficiência.

O processo de modificabilidade cognitiva estrutural compreende a consciência do sujeito durante a realização das tarefas do programa proposto por Feuerstein, promovendo "insights", sendo o próprio aluno detector da evolução do seu conhecimento. Esse processo resulta da interação entre o sujeito e uma nova cultura ao qual será exposto. Responder aos estímulos desse novo meio propiciará ser também agente transformador que determinará seu próprio caminho para a individuação.

A modificabilidade cognitiva estrutural está relacionada à autonomia do sujeito proporcionada pelas aprendizagens superiores desenvolvidas, (perceber, reter atenção, concentrar, memorizar, pensar...) que faz com que as pessoas com história de deficiência digam "não" a limitação do ambiente em que são inseridas. Esses ambientes precisam conter estímulos necessários que propiciem o desenvolvimento e a modificação de padrões pré determinados, como a necessi- 
dade de desafiar os padrões fixos da escola tradicional, onde o que é destinado como aprendizado para o deficiente, na maioria das vezes, resulta apenas em"treinamento" para atividades quotidianas.

Durante sua pesquisa Silvia comprovou que a forma tradicional de ensino pode ser repensada escrevendo em seu livro algumas frases que denotam o desenvolvimento cognitivo do grupo durante a sua pesquisa, como: "Não me aceite como eu sou" e "Espera aí, você é um cara inteligente, não faz isso comigo". Esses exemplos foram resultados do instrumento ${ }^{2}$ (PEI) utilizado, segundo a teoria feuersteniana, seguida pela autora e que vale a pena ser conferido mais minuciosamente no capítulo 4 "Uma história na qual modificar foi possível".

Em uma de suas conclusões, Silvia deixa claro que a qualidade da interação com os sujeitos do grupo de adultos, bem como a direção das atividades para promover as aprendizagens superiores, ao aumentar gradualmente o nível de complexidade nas tarefas, constitui o alicerce para a modificabilidade. A ação executada, de elaborar hipóteses a cerca das tarefas apresentadas, considerar referências de espaço e tempo e dar significado as palavras por meio da linguagem complexa utilizada pelas mediadoras, fez com que ficasse cada vez mais perceptível o desenvolvimento das aprendizagens cognitivas superiores no grupo de adultos. Isso quer dizer que um ato mental superior, ou seja, a construção de conceitos, sobrepassa a mera descrição dos fatos sem relevância para o processo de construção do pensamento.

A proposta pedagógica de Feuerstein supõe um trabalho de construção por meio da interação e a disposição à transformação que pode ocorrer no sujeito.
A mudança ocorrida é algo que se define e redefine constantemente, visando o sujeito em relação à sociedade como dinâmico e interativo.

Um dos principais aspectos conclusivos da autora após sua experiência nessa pesquisa é muito bem descrito no que Silvia (p. 119) denomina a base teóricofilosófica de sua vivência, em que a frase "Não me aceite como eu sou", vem rodeada de "porquês" explicativos como: "fica decretada a proibição" da predição; o homem, ele próprio, produz-se como ser modificável; é direito do "deficiente" modificar-se; é um compromisso dos profissionais dessa área, especificamente, e da sociedade em geral, garantir esse direito inalienável; a relação homem/mundo é mediada pela cultura e, dessa maneira, é a própria cultura que precisa empunhar a bandeira do "Não me aceite como eu sou"; mesmo que a autonomia do homem seja considerada algo relativo (uma vez que homem e relações sociais interagem dialeticamente), é preciso não perdê-la de vista.

Por fim, essa obra é um importante referencial para pedagogos, psicólogos e profissionais que atuam em educação especial (embora a teoria feuersteniana possa ser aplicada em qualquer contexto educacional), que desejem ser audaciosos em suas mediações com os alunos, com os quais trabalham. Para quem nunca ouviu falar em nada que seja capaz de processar mudanças cognitivas - de conhecer, em pessoas com história de deficiência mental, aí está o livro de Silvia Zanatta Da Ros provando que modificar é possível.

Enviado: 26/06/2004 Revisado: 20/09/2004 Aceito: $25 / 10 / 2004$

\section{Notas:}

${ }^{1} \mathrm{O}$ outro na perspectiva feuersteniana significa mediador, e o processo de interação do outro no meio significa mediação.

${ }^{2}$ Os Instrumentos dizem respeito ao PEI (Programa de Enriquecimento Instrumental).

\section{Sobre as autoras da Resenha:}

Jorgiana Baú: Professora da Universidade do Oeste de Santa Catarina - Campus Joaçaba. Mestranda do Programa de Pós-Graduação em Psicologia da Universidade Federal de Santa Catarina convênio UNOESC.

Olga Mitsue Kubo: Doutora em Psicologia Experimental pela Universidade de São Paulo. Professora do Programa de Pós-Graduação em Psicologia da Universidade Federal de Santa Catarina. 